\title{
Welcome message from the new editor
}

\section{Gregory S. Zaric ${ }^{1}$}

Published online: 14 February 2020

(C) Springer Science+Business Media, LLC, part of Springer Nature 2020

I am pleased to write my first editorial as Editor in Chief of Health Care Management Science.

I will begin by thanking a number of people. First, I would like to thank the Founding Editor in Chief, Yasar Ozcan, who has retired after a long career in academia and 22 years of service to the journal. Yasar's stewardship has left the journal in a healthy position, with steadily increasing submission volumes and steadily increasing impact. I thank the previous Editorial Board for their longstanding commitment to the journal. Their work has helped to boost the profile of the journal and to ensure high editorial standards. I would also like to thank the members of the new Editorial Board. Many previous Board members remain on the Board, and several new people have graciously agreed to join the board. The new board is much larger than the previous board and it has a new structure. To maintain high editorial standards, the goal is that all papers sent for review will be reviewed by at least one member of the Editorial Board. Finally, I would like to thank the team at Springer Nature for continuing to support this important journal.

Health Care Management Science will continue to serve as an outlet for high-quality research in which management science and quantitative analysis is applied to challenging problems in health care. I have updated the journal "Aims and Scope" to clearly communicate the focus of the journal on real-world problems in health care and important methodological contributions to the field of health care management science. There are three important components of the new Aims and Scope statement. First, a clarification that papers should deal with "health care delivery, health care management, and health care policy". In other words, papers should fundamentally be about a real health care problem. Second, a range of methods has been specified. The goal is to remain devoted to advanced quantitative methods, while encouraging submissions using a wide variety of techniques. Third, the Aims and Scope statement reflects an interest in applied research, particularly when the papers are accompanied by evidence of the impact of the work.

The journal will continue to publish Original Research articles and a limited number of review articles. I am excited to introduce a new article type called "Current Opinion". Current Opinion articles are intended to be short pieces describing how the tools, methods, or literature from the field could help inform current debates. Topics could range from emerging epidemics to detailed changes in regulatory frameworks. These articles will be reviewed quickly, and authors will be given a very short turnaround time to respond to reviewer feedback. This will allow Current Opinion articles to be posted on the web site quickly. I hope that these articles will attract attention to the journal, and, more importantly, get insights from our field into the public domain fast enough to be relevant to public debate. The journal will also be interested in greater use of "Letters to the Editor" in cases where researchers want to respond directly to a recent article.

This is an exciting time for the journal. I look forward to working with authors, the Editorial Board, and the team at Springer Nature, to make Health Care Management Science a leading outlet for work in the space.

Greg Zaric.
Gregory S. Zaric

gzaric@ivey.ca

1 Western University, London, ON, Canada 